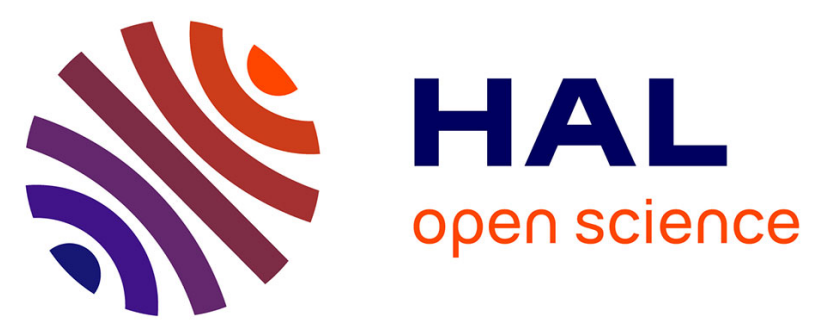

\title{
A comparative study on the enzymatic biodegradability of covalently functionalized double- and multi-walled carbon nanotubes
}

Gloria Modugno, Fayçal Ksar, Alessia Battigelli, Julie Russier, Pierre Lonchambon, Edelma Eleto da Silva, Cécilia Ménard-Moyon, Brigitte Soula, Anne-Marie Galibert, Mathieu Pinault, et al.

\section{To cite this version:}

Gloria Modugno, Fayçal Ksar, Alessia Battigelli, Julie Russier, Pierre Lonchambon, et al.. A comparative study on the enzymatic biodegradability of covalently functionalized double- and multi-walled carbon nanotubes. Carbon, 2016, 100, pp.367-374. 10.1016/j.carbon.2016.01.023 . hal-01486989

\section{HAL Id: hal-01486989 \\ https://hal.science/hal-01486989}

Submitted on 10 Mar 2017

HAL is a multi-disciplinary open access archive for the deposit and dissemination of scientific research documents, whether they are published or not. The documents may come from teaching and research institutions in France or abroad, or from public or private research centers.
L'archive ouverte pluridisciplinaire HAL, est destinée au dépôt et à la diffusion de documents scientifiques de niveau recherche, publiés ou non, émanant des établissements d'enseignement et de recherche français ou étrangers, des laboratoires publics ou privés. 


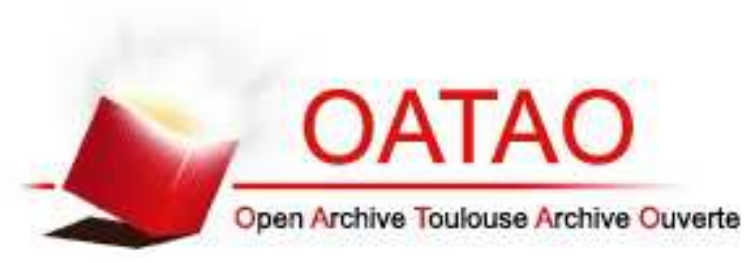

\section{Open Archive TOULOUSE Archive Ouverte (OATAO)}

OATAO is an open access repository that collects the work of Toulouse researchers and makes it freely available over the web where possible.

This is an author-deposited version published in : http://oatao.univ-toulouse.fr/ Eprints ID : 16739

To link to this article : DOI:10.1016/j.carbon.2016.01.023

URL : http://dx.doi.org/10.1016/j.carbon.2016.01.023

To cite this version : Modugno, Gloria and Ksar, Fayçal and Battigelli, Alessia and Russier, Julie and Lonchambon, Pierre and Eleto da Silva, Edelma and Ménard-Moyon, Cécilia and Soula, Brigitte and Galibert, Anne-Marie and Pinault, Mathieu and Flahaut, Emmanuel and Mayne-L'Hermite, Martine and Bianco, Alberto $A$ comparative study on the enzymatic biodegradability of covalently functionalized double- and multi-walled carbon nanotubes. (2016) Carbon, vol. 100. pp. 367-374. ISSN 0008-6223

Any correspondence concerning this service should be sent to the repository administrator: staff-oatao@ listes-diff.inp-toulouse.fr 


\title{
A comparative study on the enzymatic biodegradability of covalently functionalized double- and multi-walled carbon nanotubes
}

\author{
Gloria Modugno a, $^{\text {, Fayçal Ksar }}{ }^{\text {b, } 1}$, Alessia Battigelli a, ${ }^{1}$, Julie Russier ${ }^{\text {, }}$ \\ Pierre Lonchambon c , Edelma Eleto da Silva ${ }^{\text {b, } 2}$, Cécilia Ménard-Moyon ${ }^{a}$, Brigitte Soula ${ }^{\text {, }}$ \\ Anne-Marie Galibert ${ }^{\mathrm{c}}$, Mathieu Pinault ${ }^{\mathrm{b}}$, Emmanuel Flahaut ${ }^{\mathrm{c}, \mathrm{d}}$, \\ Martine Mayne-L'Hermite ${ }^{b}$, Alberto Bianco ${ }^{\text {a, * }}$ \\ a CNRS, Institut de Biologie Moléculaire et Cellulaire, Laboratoire d'Immunopathologie et Chimie Thérapeutique, 67000 Strasbourg, France \\ b NIMBE, CEA, CNRS, Université Paris-Saclay, CEA Saclay, 91191 Gif-sur-Yvette, France \\ ' Université de Toulouse, INP, UPS, Institut Carnot CIRIMAT (Centre Inter-universitaire de Recherche et d'Ingénierie des Matériaux), UMR CNRS 5085, \\ F-31062 Toulouse cedex 9, France \\ d CNRS, Institut Carnot CIRIMAT, F-31062 Toulouse, France
}

\begin{abstract}
A B S T R A C T
The assessment of the biodegradability potential of carbon nanotubes (CNTs) is a fundamental point towards their applications in materials science and biomedicine. Due to the continuous concerns about the fate of such type of nanomaterials, it is very important to understand if they can undergo degradation under certain conditions and if the morphology and structure of the nanotubes play a role in this process. For this purpose we have decided to undertake a comparative study on the enzymatic degradation of CNTs with concentric multilayers. Double-walled (DW) and multi-walled (MW) CNTs of various lengths, degrees of oxidation and functionalizations using different methods were treated with horseradish peroxidase (HRP). While all tested DWCNTs resulted resistant to the biodegradation, some of the MWCNTs were partially degraded by the enzyme. We have found that short oxidized multi-walled CNTs functionalized by amidation were reduced in length and presented a high amount of defects at the end of the period of treatment with HRP. This comparative study holds its importance in the understanding of the structural changes of different types of nanotubes towards the catalytic enzymatic degradation and will help to design safer CNTs for future applications.
\end{abstract}

\section{Introduction}

Due to their unique physicochemical, optical, and mechanical properties, carbon nanotubes (CNTs) are promising nanomaterials for a wide range of applications both in materials science [1] and biomedicine [2-4]. In particular, since CNTs present a high surface area, the chemistry of functionalized CNTs ( $f$-CNTs) has been extensively investigated through the derivatization of their external tips and sidewalls [5]. Today, the increasing production of CNTs, together with their incorporation into new types of

\footnotetext{
* Corresponding author.

E-mail address: a.bianco@ibmc-cnrs.unistra.fr (A. Bianco).

1 These authors contributed equally to the work.

2 Permanent address: UNIFEI - Campus Avançado de Itabira, Itabira - Minas Gerais, Brazil.
}

composites and/or into biological systems have raised fundamental issues on their impact on human health and environment [6-8]. However, studies on the biopersistence and the fate of the CNTs, once released into the natural environments, are still limited. Particularly, the biodegradation of CNTs could help to avoid possible risk of contamination, pollution and damages to the living systems. Generally, the fate of CNTs in the environment may depend on specific properties such as functionalization, length and aggregation state [9].

Recently, few groups have reported the degradation of CNTs catalyzed by naturally occurring enzymes from plants and humans or by action of microorganisms [10-22]. Most of the degradation studies reported concern oxidized CNTs (ox-CNTs). In fact, the process of oxidation is often used to shorten pristine CNTs and to improve their dispersibility, by introducing carboxylic functions at the tips and the defect sites. Recent studies have shown the 
capacity of carboxylated single-walled CNTs (SWCNTs) to be abiotically degraded, within 10 days, by horseradish peroxidase (HRP) in the presence of low concentration of hydrogen peroxide $[17,20]$. The defect sites, introduced by the oxidation, clearly enhance the biodegradation rate, under the enzymatic oxidative conditions. Carboxylated SWCNTs can be also degraded inside the cells such as neutrophils and macrophages by the action of myeloperoxidase [16]. Other enzymes of potential interest for CNT biodegradation include ligninolytic heme peroxidases, such as manganese peroxidase (MnP) [21] and lactoperoxidase (LiP) [22]. These enzymes have shown oxidizing capacity against pristine and carboxylated SWCNTs.

While most of the degradation studies in the literature focus on SWCNTs, few studies concerned the possible degradation of CNTs with multiple concentric layers [i.e. multi-walled (MW) and double-walled (DW) CNTs]. Due to their more complex structure, these types of tubes are expected to be less sensitive to enzymatic degradation. Cellular degradation of DWCNTs was observed by using Raman spectroscopy to monitor changes in the carbon lattice [23]. Defects seemed to accumulate on the external graphene sheet of the nanotubes after internalization by human prostate adenocarcinoma cells. Moreover, carboxylated MWCNTs exposed to HRP/ $\mathrm{H}_{2} \mathrm{O}_{2}$ treatment, over 60 days, were observed to undergo a degradation process, leading to shortened nanotubes and carbonaceous fragments [13]. The concurrent reduction in diameter of the tubes could be explained by exfoliation of defect-containing outer carboxylated walls, which were unzipped via the enzymatic oxidation, yielding bare CNTs with smaller diameters and possessing defectless surfaces. The exposure of the novel layers coincided with a reduction in the rate of degradation, highlighting that the number of walls is a crucial parameter that affects the biodegradability of CNTs. Independently, we also demonstrated that carboxylated MWCNTs underwent morphological changes (i.e. shortening and deformation) when incubated with $\mathrm{HRP}$ and $\mathrm{H}_{2} \mathrm{O}_{2}$ [14]. Contrary to the previous report, the results suggested that the biodegradation reduce the length of the tubes, creating a higher amount of defects on their walls, rather than exfoliating their external surface. In addition, Zhang et al. demonstrated the ability of some bacteria to degrade acid-treated MWCNTs under environmentally relevant conditions, leading to a decrease of their environmental persistence [18]. Very recently, we have demonstrated that specific functional molecules linked to CNTs can enhance the catalytic activity of HRP towards the degradation of multi-walled CNTs [24]. Coumarin derivatives and catechol were covalently conjugated to oxidized MWCNTs (ox-MWCNTs). These molecules are efficient reducing substrates for HRP. In addition, catechol is also a strong redox mediator of HRP as it favors electron transfer and prevents the enzyme inactivation. Other studies have evidenced the persistence and degradation of CNTs in vitro and in vivo. Sato et al. have shown the long-term biopersistence of tangled oxMWCNTs in vivo, demonstrating their potential use as biological implantable materials [25]. In that study, ox-MWCNTs were implanted into rat subcutaneous tissues. Two years after the implantation, high resolution transmission electron microscopy (HRTEM) and Raman spectroscopy were used to assess if the nanotubes did undergo structural changes. Large agglomerates of $o x$-MWCNTs were present in the intercellular space and were not degraded. On the contrary, small agglomerates were engulfed by macrophages, where they were gradually degraded in lysosomes. No early stages of severe changes, such as necrosis and carcinogenesis, were observed in the tissues. More recently, another work also reported superior in vivo biodegradability of MWCNTs functionalized by Diels-Alder reaction and further oxidized to generate $\mathrm{COOH}$ groups, in comparison to pristine nanotubes [26]. The group of A. E. Porter has shown the effects of the functionalization and aggregation state of MWCNTs on internalization and biopersistence in microglia [27]. Dynamic processes of disentanglement of aggregates of ox-MWCNTs by microglia were observed by high resolution and dynamic imaging, triggering their internalization. This process of disentanglement did not occur with pristine MWCNTs. Some indications of damages to the structure of ox-MWCNTs suggested possible biodegradation.

The results discussed above clearly evidence that the defects or the sites of functionalization are important promoters of enzymatic action. As a consequence, we have chosen to extend the degradation studies to different types of functionalized CNTs with multiple concentric walls, not only bearing simple carboxylic functions. Particularly, chemical derivatization of CNTs is also of fundamental importance in order to reduce the undesired effects, enabling these materials to be used more widely in a safe manner [28]. Indeed, organic functionalization of CNTs is often used to increase their dispersibility in water, control their length and enhance their biocompatibility [5]. Low toxicity of CNTs has been also correlated to the presence of functional groups on the external surface of the tubes [29]. Thus, with the aim to render the nanotubes more biodegradable, MWCNTs and DWCNTs have been submitted to different chemical acid treatments, yielding oxidized tubes with different length and morphology. Moreover, we have introduced amino groups both onto the sidewalls and at the tips of oxidized CNTs using amidation and 1,3-dipolar cycloaddition reactions. Finally, we have investigated and compared the catalytic biodegradation of the different functionalized CNTs by incubation with HRP in test tubes. To enable the enzymatic activity, hydrogen peroxide was added daily (i.e. 6 times/day). The changes in nanotube morphology were observed by transmission electron microscopy (TEM) at different time points up to 20 days. Finally, their structures were further analyzed by Raman spectroscopy.

\section{Experimental}

Details on the materials, the instruments, the synthesis of DWCNTs and MWCNTs and the functionalized nanotubes, and the procedure for the enzymatic degradations are reported in the Supporting Information.

\section{Results and discussion}

\subsection{Oxidation and organic functionalization of multi- and double- walled CNTS}

In this work, we have compared the functionalization degree and the biodegradation properties of oxidized and functionalized CNTs with multiple concentric layers. Initially, different chemical treatments allowed to obtain a library of precursor CNTs differing in (i) length, (ii) number of layers (MW or DW) and (iii) amount of $\mathrm{COOH}$ functionalities. Table 1 displays the characteristics of the nanotubes, following the chemical treatments. Pristine MWCNTs exhibited an average length of $500 \mu \mathrm{m}$ and a mean external diameter of $24 \mathrm{~nm}$ [30]. The outer and inner average diameters of

Table 1

Characteristics of the precursor CNTs used for the functionalization reactions.

\begin{tabular}{llll}
\hline Entry & Oxidized CNTs & Average length $(\mu \mathrm{m})$ & O/C atomic ratio (\%) $(\mathrm{XPS})$ \\
\hline 1 & L-MW 1 & $5.4 \pm 4.4$ & 0.7 \\
2 & S-MW 2 & $1.2 \pm 0.6$ & 0.7 \\
3 & L-MW 3 & $1.1 \pm 0.7$ & 5.6 \\
4 & S-MW 4 & $1.3 \pm 1.0$ & 4.5 \\
5 & DW 5 & ND $^{\mathrm{a}}$ & 1.0 \\
\hline
\end{tabular}

a (ND: non-determined). 
L-MW 3

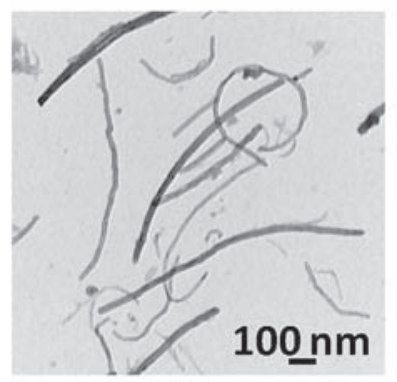

S-MW 4

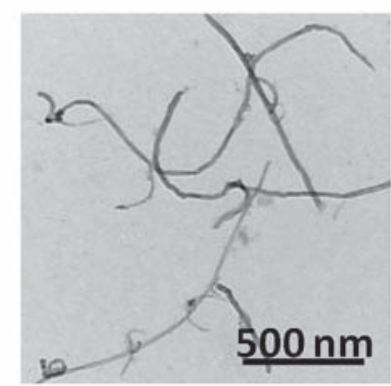

DW

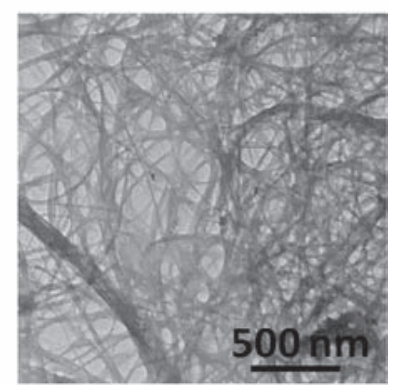

Fig. 1. TEM images of oxidized (long and short) multi (MW)- and double (DW)-walled CNTs.

the MWCNTs were 20-30 $\mathrm{nm}$ and 5-10 nm, respectively. We estimated the number of walls $(\sim 20-30)$ based on the sheet interlayer distance $(0.34 \mathrm{~nm})$.

With the aim to obtain tubes with two different lengths, pristine MWCNTs were extensively sonicated in isopropyl alcohol (iPrOH). Following this treatment, the average length of the long tubes (nominated L-MW) was $5.4 \mu \mathrm{m}$ after $12 \mathrm{~h}$ sonication (entry 1). MWCNTs, submitted to longer sonication treatment in $i \operatorname{PrOH}(24 \mathrm{~h})$, and indicated as short MWCNTs (nominated S-MW, entry 2) exhibited a mean length of $1.2 \mu \mathrm{m}$. Moreover, as biodegradation increased with the introduction of functional groups, we submitted both long and short nanotubes to chemical oxidative treatments, using strong acidic conditions $\left(\mathrm{H}_{2} \mathrm{SO}_{4} / \mathrm{HNO}_{3}, 3: 4\right)$ (entry 3-4). The oxidation procedure allowed also to obtain even shorter CNTs (Fig. 1), mainly endowed of carboxylic groups at their tips and sidewalls (Fig. 2).

$\mathrm{X}$-ray photoelectron spectroscopy (XPS) indicated that the $\mathrm{O} / \mathrm{C}$ atomic ratio increased from $0.7 \%$ to $5.6 \%$ and $4.5 \%$ after oxidation for
L-MW 3 and S-MW 4, respectively (Table 1, Fig. 2 and Figure S1 in Supporting Information). TGA performed under nitrogen showed that the pristine long MWCNTs L-MW 1 and short MWCNTs S-MW $\mathbf{2}$ were stable in inert atmosphere, while a significant weight loss attributed to oxygenated species was observed after oxidation in both cases (Fig. 3). The weight loss of S-MW 4 was drastically higher than that observed for L-MW 3, which is indicative of a higher content of oxygenated species. The O/C atomic ratio for S-MW 4 assessed by XPS was instead slightly lower compared to the value for L-MW 3. The TGA results are indicative of a high oxidation level for the short MWCNTs, which suggests that oxygenated species are not only localized at the nanotube surface, but also in CNT bulk as indicated by HRTEM analysis, showing defects even in the inner CNT walls (see Figure S2). XPS is a surface analysis with limited probing depth (estimated to $10-15 \mathrm{~nm}$ in carbon materials), while TGA is a bulk analysis. Therefore, the $\mathrm{O} / \mathrm{C}$ ratio obtained by XPS is likely underestimated. Oxidized DWCNTs were obtained from pristine nanotubes by treatment using the following conditions: i)
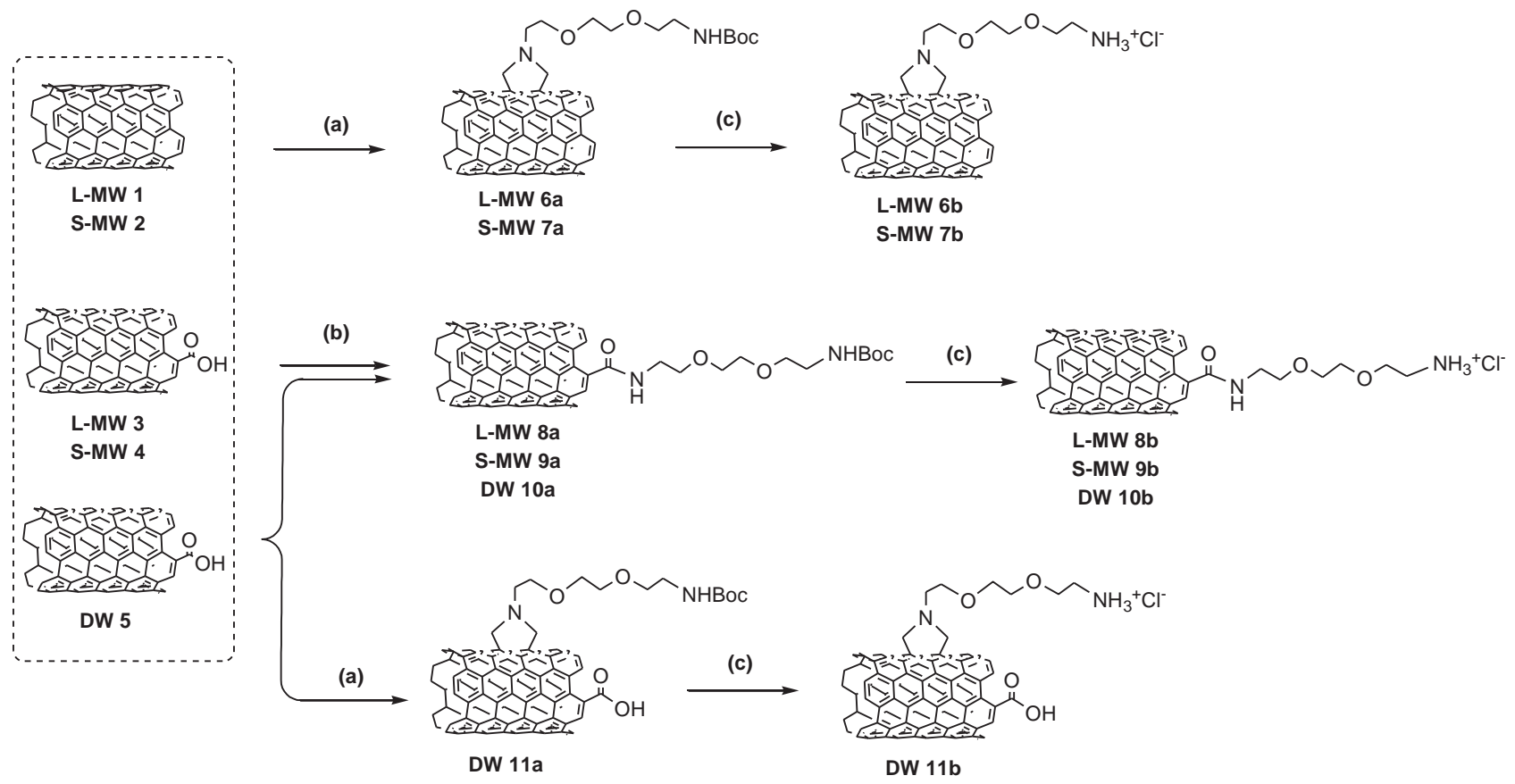

$\mathrm{i}_{\text {HOO }} \stackrel{\mathrm{O}}{\mathrm{H}} \mathrm{H}_{\mathrm{O}}^{\mathrm{N}} \sim \sim_{\mathrm{NHBoc}}$

ii $\mathrm{H}_{2} \mathrm{~N} \sim \sim_{\mathrm{O}} \sim \sim_{\mathrm{NHBoc}}$

Fig. 2. Synthetic routes for the functionalization of the precursor CNTs. (a) 1,3-Dipolar cycloaddition reaction: i, $\left(\mathrm{CH}_{2} \mathrm{O}\right)_{\mathrm{n}}, \mathrm{DMF}, 125{ }^{\circ} \mathrm{C}, 24 \mathrm{~h}$ or $72 \mathrm{~h}$; (b) amidation reaction: 1$) \mathrm{SOCl}{ }_{2}$ or $\mathrm{COCl}_{2}$, reflux, $24 \mathrm{~h} ; 2$ ) ii, THF, reflux, 48 h; (c) deprotection: $\mathrm{HCl}$ in 1,4-dioxane, rt, overnight. 
$\mathrm{HNO}_{3}\left(3 \mathrm{M}, 130{ }^{\circ} \mathrm{C}, 24 \mathrm{~h}\right)$, ii) $\mathrm{H}_{2} \mathrm{SO}_{4} / \mathrm{HNO}_{3}\left(3: 1,70{ }^{\circ} \mathrm{C}, 5 \mathrm{~h}\right)$, and iii) $\mathrm{NaOH}$ washing (4 M) (Table 1, entry 5 ). As it is evident from TEM images reported in Fig. 1, oxidized DWCNTs show a different behavior respect to oxidized MWCNTs. Since nanotubes with a double wall are more prone to form strong aggregates, their
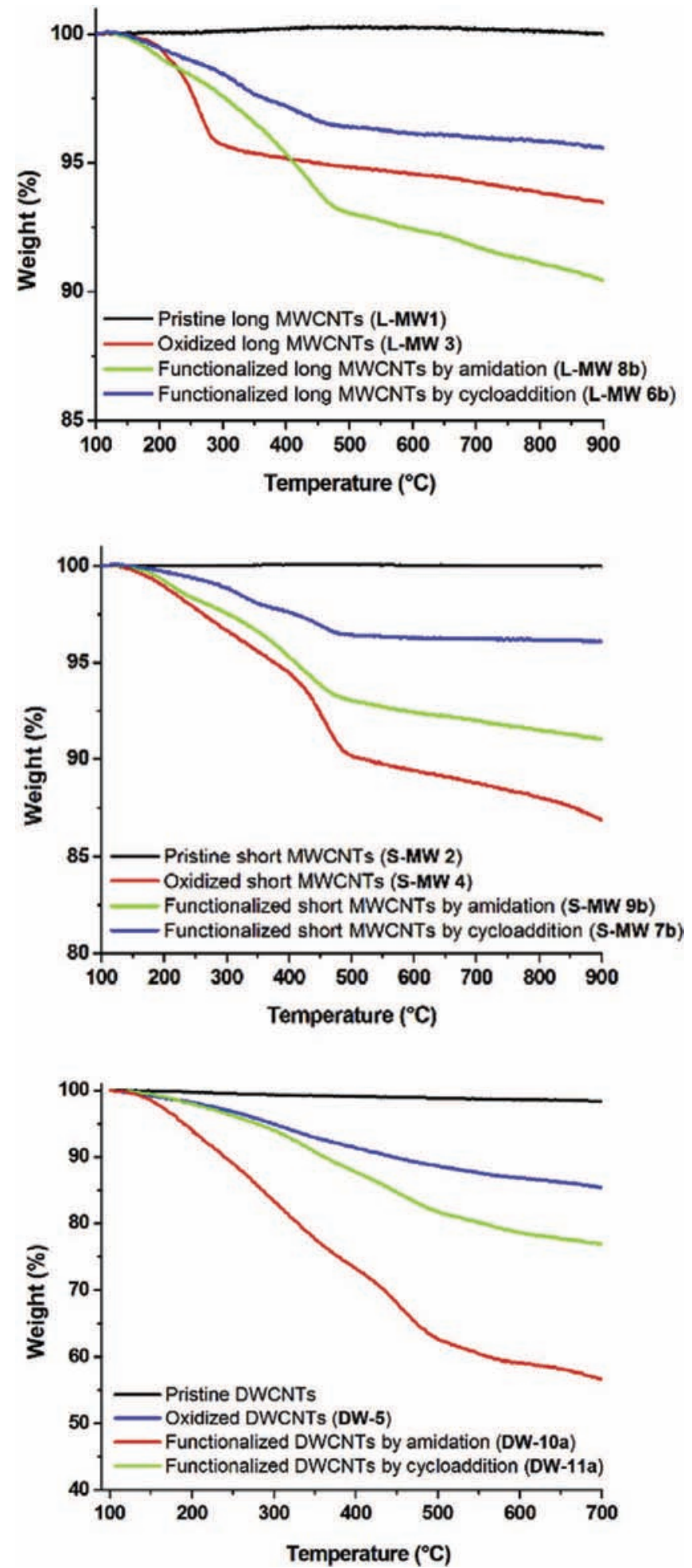

Fig. 3. Top: TGA of the pristine (L-MW 1), oxidized (L-MW 3), and long f-MWCNTs (LMW 6b and L-MW 8b); Middle: TGA of the pristine (S-MW 2), oxidized (S-MW 4), and short $f$-MWCNTs (S-MW 7b and S-MW 9b); Bottom: TGA of the pristine, oxidized (DW 5), and Boc-protected $f$-DWCNTs (DW 10a and DW 11a). (A color version of this figure can be viewed online.) dispersibility in both organic solvents and water resulted much lower [31]. The CNTs described in Table 1 (entry 1-5) were used as precursor CNTs for further functionalization reactions. Indeed, the oxidative treatments not only contribute to shorten the CNTs, but offers also an anchor point for further covalent derivatization of the nanotubes (Fig. 2).

Initially, L-MW 1, S-MW 2 and DW 5, were functionalized by 1,3dipolar cycloaddition of azomethine ylides, using a triethylene glycol $\mathrm{N}$-modified amino acid with the terminal amine group protected with Boc, to afford L-MW 6a, S-MW 7a and DW 11a, respectively [Fig. 2, route (a)]. In parallel, the carboxylic groups of the oxidized CNTs (i.e. L-MW 3, S-MW 4 and DW 5) were directly converted into the corresponding amides L-MW 8a, S-MW 9a and DW 10a respectively, through condensation with Bocmonoprotected diaminotriethylene glycol [Fig. 2, route (b)]. Boc protecting groups were then cleaved using a solution of $\mathrm{HCl}$ in 1,4dioxane, affording ammonium-functionalized L-MW 6b, S-MW 7b, L-MW 8b, S-MW 9b, DW 10b and DW 11b [Fig. 2, route (c)].

TGA was again used to confirm the successful functionalization of both long and short MWCNTs (Fig. 3). A significant weight loss was observed after functionalization by 1,3-dipolar cycloaddition compared to the pristine long MWCNTs L-MW 1 (Fig. 3, top). The weight loss of the amidated long MWCNTs L-MW 8b was higher compared to the oxidized long MWCNTs L-MW 3, confirming that the $\mathrm{COOH}$ groups have been derivatized with the diaminotriethylene glycol chain. In the case of the short MWCNTs, the thermal profile of the nanotubes functionalized by cycloaddition and amidation is rather similar to that of the functionalized long MWCNTs, respectively (Fig. 3, middle).

Surprisingly, the weight loss after amidation was lower in comparison to that of the short oxidized MWCNTs S-MW 4. We tried to hypothesize that this unexpected behavior might be due to the removal of some labile oxygenated groups from the nanotube surface in the conditions used to perform the amidation. Finally, in the case of the DWCNTs, the weight loss is minimal for the pristine DWCNTs, while there is an increased weight loss after oxidation and further functionalization by 1,3-dipolar cycloaddition and amidation (Fig. 3, bottom). The level of functionalization was higher for DWCNTs obtained by amidation reaction (DW 10a) compared to those functionalized by cycloaddition (DW 11a).

After deprotection of the Boc groups, the amount of free amino groups on the different conjugates was assessed using the Kaiser test. The level of functionalization was similar for long and short oxidized MWCNTs functionalized by amidation: 221 (L-MW 8b) and $204 \mu \mathrm{mol}$ (S-MW 9b) of amino functions per gram of $f$-CNTs, respectively (Table 2). The degree of functionalization was lower for long and short oxidized MWCNTs functionalized by 1,3-dipolar cycloaddition: 14 (L-MW 6b) and $23 \mu \mathrm{mol} / \mathrm{g}$ (S-MW 7b), respectively. In the case of functionalized DWCNTs, we obtained a loading of 82 (DW 11b) and $275 \mu \mathrm{mol} / \mathrm{g}$ (DW 10b) for the cycloaddition and the amidation, respectively.

\subsection{Biodegradation of functionalized multi- and double-walled CNTS}

All degradation studies have been carried out by incubating the different CNTs $(10 \mu \mathrm{g} / \mathrm{mL})$ with HRP $(20 \mathrm{U} / \mu \mathrm{g} / \mathrm{mL})$ in phosphate buffer saline solution. To enable the enzymatic activity, a solution of $\mathrm{H}_{2} \mathrm{O}_{2}$ was added daily every $2 \mathrm{~h}$ for a total of 6 times per day. The solutions were kept in the dark and stirred at $25{ }^{\circ} \mathrm{C}$ for the entire duration of the experiment (20 days). In comparison to our previous procedure [14], this protocol resulted in an acceleration of the degradation process of CNTs. Aliquots were taken at time 0,10 and 20 days, and stored at $-20{ }^{\circ} \mathrm{C}$ in the dark until characterization by TEM and Raman spectroscopy. The latter technique is generally 
Table 2

Changes of the structural parameters to monitor oxidized and $f$-CNT biodegradation.

\begin{tabular}{|c|c|c|c|c|c|c|c|}
\hline \multirow[t]{2}{*}{ Entry } & \multirow[t]{2}{*}{ CNT } & \multirow[t]{2}{*}{ Functionalization } & \multirow[t]{2}{*}{ Amount of functional groups ${ }^{\mathrm{a}}(\mu \mathrm{mol} / \mathrm{g})$} & \multicolumn{2}{|c|}{$\mathrm{I}_{\mathrm{D}} / \mathrm{I}_{\mathrm{G}}^{\mathrm{b}}$} & \multicolumn{2}{|c|}{$\begin{array}{l}\text { Average length }{ }^{c} \\
(\mathrm{~nm})\end{array}$} \\
\hline & & & & (d0) & $(\mathrm{d} 20)$ & (d0) & $(\mathrm{d} 20)$ \\
\hline 1 & L-MW 3 & $\mathrm{COOH}$ & - & 0.25 & 0.22 & 1200 & 660 \\
\hline 2 & L-MW 6b & cycloaddition & 14 & 0.23 & 0.25 & 2830 & 1310 \\
\hline 3 & L-MW 8b & $\mathrm{COOH} /$ amidation & 221 & 0.38 & 0.42 & 2020 & 1450 \\
\hline 4 & S-MW 4 & $\mathrm{COOH}$ & - & 0.52 & 0.46 & 1350 & 1230 \\
\hline 5 & S-MW 7b & cycloaddition & 23 & 0.23 & 0.28 & 990 & 930 \\
\hline 6 & S-MW 9b & $\mathrm{COOH} /$ amidation & 204 & 0.39 & 0.64 & 1380 & 900 \\
\hline 7 & DW 5 & $\mathrm{COOH}$ & - & 0.05 & 0.06 & ND & ND \\
\hline 8 & DW 11b & $\mathrm{COOH} /$ cycloaddition & 82 & 0.05 & 0.08 & ND & ND \\
\hline 9 & DW 10b & $\mathrm{COOH} /$ amidation & 275 & 0.05 & 0.05 & ND & ND \\
\hline
\end{tabular}

ND: not determined.

a Calculated by Kaiser test.

b Calculated by Raman spectroscopy ( $\mathrm{I}_{\mathrm{D}}$ : D band intensity; $\mathrm{I}_{\mathrm{G}}$ : G band intensity) for day 0 (d0) and 20 days (d20) after the treatment with HRP.

c Measured by TEM.

L-MW 3

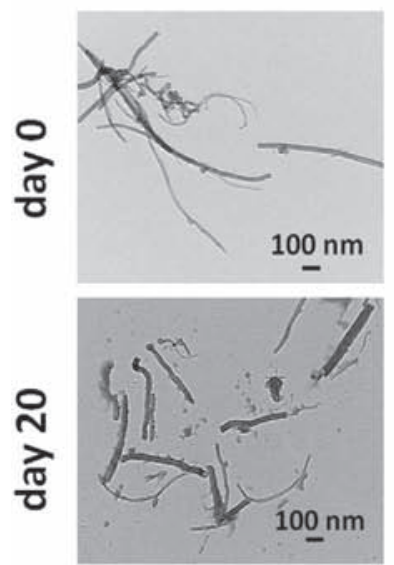

L-MW 6b
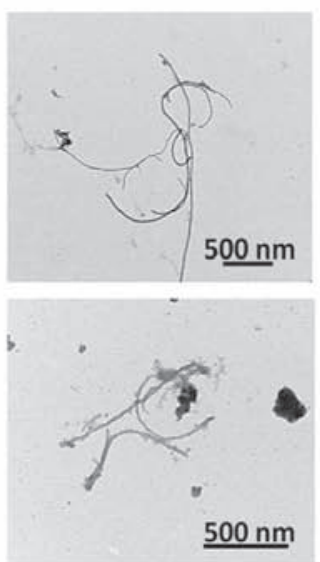

L-MW 8b
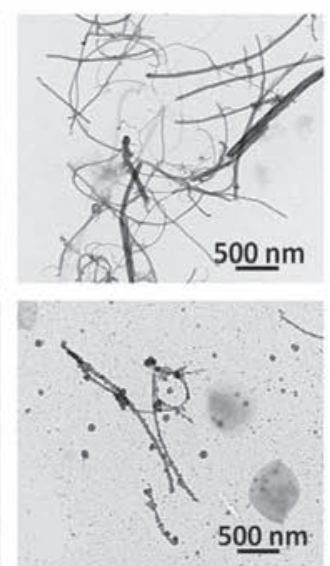

S-MW 4
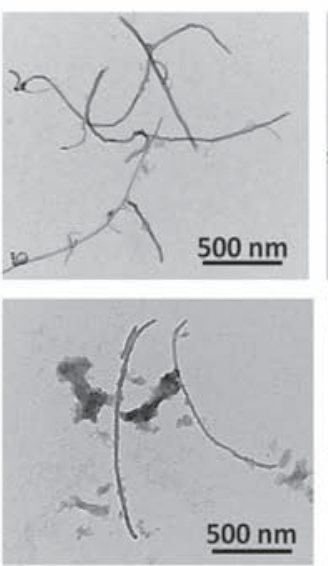

S-MW 7b
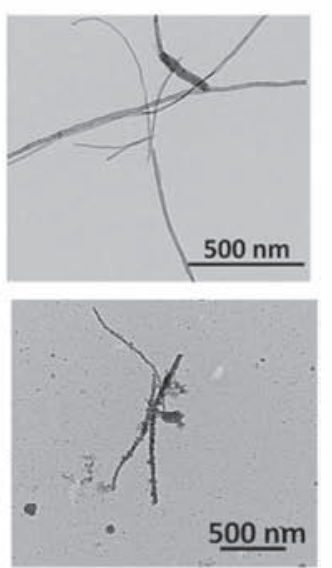

Fig. 4. TEM images of L-MW 3, L-MW 6b, L-MW 8b, S-MW 4 and S-MW 7b (from the left) during the degradation process. The samples were observed after 20 days and compared to the starting material (day 0 ).

useful for the characterization of CNTs to evidence the variation of the intensity of the $D$ band (frequency at $\sim 1350 \mathrm{~cm}^{-1}$ ) to the $G$ band (frequency at $\sim 1590 \mathrm{~cm}^{-1}$ ), and therefore the defect density on the nanotubes. More precisely, the D band is associated to the functional groups and defects generated by both the initial acidic treatment and the functionalization. Hence, the progressive variation of this band can suggest that the tubes are undergoing morphological modifications, as a result of the biodegrading action [14]. In particular, in the case of MWCNTs, although they already exhibit an intense D band as compared to DWCNTs, the biodegradation process in the presence of hydrogen peroxide creates more defects on the nanotubes, giving rise to an increase of this characteristic band. We have reported Raman spectra normalized to the $G$ band because absolute values should be normalized on the volume of homogenous samples, which are very difficult to obtain. Therefore, the Raman spectra allow the monitoring of the qualitative evolution of defects on the nanotubes up to complete disappearance of the signal if total CNT degradation is achieved (see Figures in Supporting Information) [14,17]. In Table 2 we have summarized the $\mathrm{I}_{\mathrm{D}} / \mathrm{I}_{\mathrm{G}}$ values for the CNTs (entry 1-9), obtained from the Raman spectra of the samples before ( $\mathrm{d} 0$ ) and 20 days (d20) after treatment with HRP. Moreover, TEM images collected before $(\mathrm{d} 0)$ and at the end ( $\mathrm{d} 20)$ of the degradation experiment allowed to monitor the morphological and length variations of the CNTs. Table 2 shows a clear dependence of the CNT biodegradation

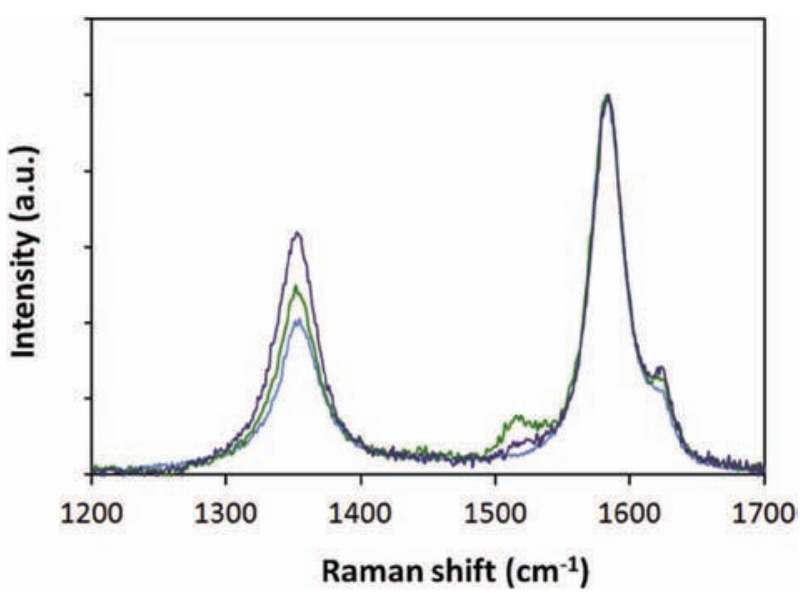

Fig. 5. Raman spectra of short $o x$-MWCNTs functionalized by amidation (S-MW 9b) during the degradation process. The sample was observed after 10 (green) and 20 days (violet). Blue line corresponds to the spectrum of the starting material. All spectra have been normalized on the $G$ band. (A color version of this figure can be viewed online.) 

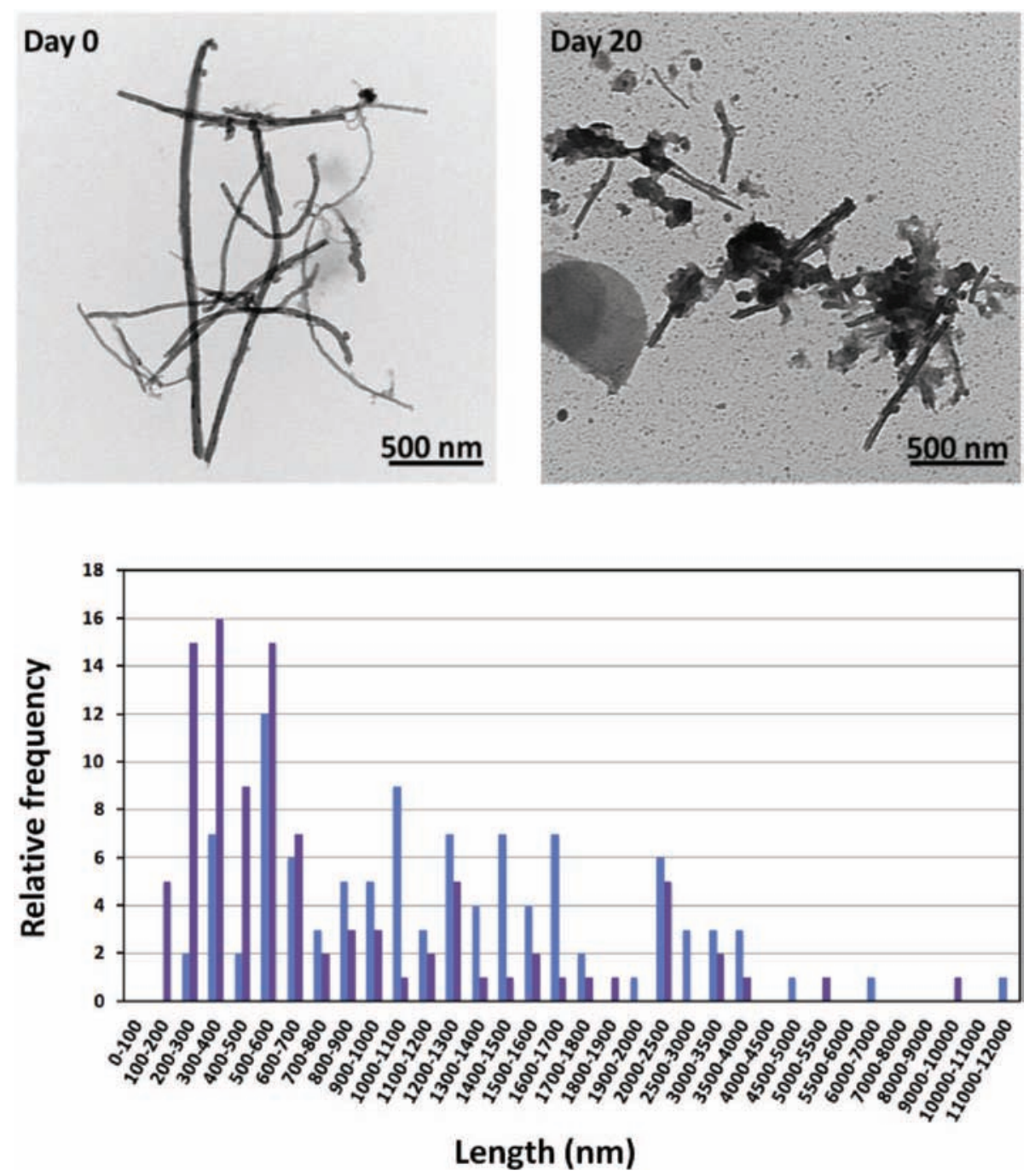

Fig. 6. Top: TEM images of short ox-MWCNTs functionalized by amidation (S-MW 9b) during the degradation process. The sample was observed before (day 0 ) and at the end of the degradation process (day 20). Bottom: statistical distribution of the length of the short ox-MWCNTs functionalized by amidation (S-MW 9b) before (blue bars) and at the end of the HRP treatment (violet bars). (A color version of this figure can be viewed online.)

on the type of functionalization. Indeed, functionalized MWCNTs showed a low variation in the D band intensity (Table 2, entry 1-5) under HRP treatment, suggesting a scarce ability of this type of $f$ CNTs to undergo degradation (vide infra). Nevertheless, in the case of long $f$-MWCNTs (entry $1-3$ ), although Raman analysis did not display any significant structural change, TEM analysis revealed a clear reduction of the length of the tubes, as a result of the action of the enzymatic process (see also Figures in Supporting Information). These data suggest that the HRP can induce the cleavage of long $f$ CNTs into shorter tubes starting from the defect sites of the external layer created by the functionalization [19]. Fig. 4 shows the TEM images of functionalized long and short MWCNTs (entry 1-5) collected during the enzymatic process.

On the contrary, a significant relative increase of the $\mathrm{D}$ band intensity, already after 10 days of enzymatic treatment, was observed for short MWCNTs functionalized by amidation (S-MW 9b, entry 6). In this specific case, the variation of the $D$ band is a clear evidence that the tubes are undergoing structural modifications, via a biodegradation process (Fig. 5).

The degradation of these CNTs is also evident from the TEM images, collected at the end of the degradation and compared to day zero. Particularly, in the TEM images of S-MW 9b, we observed many small fragments and carbonaceous debris of nanotubes that are indicative of an efficient oxidative enzymatic action (Fig. 6, top). The length of the nanotubes seems also significantly reduced. Fig. 6 (bottom) displays the statistical length distribution measured by TEM of short $o x$-MWCNTs functionalized by amidation before and after treatment with HRP. S-MW 9b became much shorter by action of HRP: the average length decreased from $1380 \mathrm{~nm}$ to $900 \mathrm{~nm}$, with $36 \%$ of the tubes shorter than $400 \mathrm{~nm}$ (Table 2, entry 6 and Fig. 6, bottom). The comparison between the TEM images and the Raman analysis suggests that the biodegrading action in the presence of hydrogen peroxide creates more defects on the nanotubes rather than exfoliating their external surface [14].

S-MW 9b, being short nanotubes functionalized by amidation, if compared to the other $f$-CNTs, present the best characteristics for undergoing an efficient biodegradation. First, the higher dispersibility of short $f$-CNTs (S-MW 7a/b and S-MW 9a/b), in comparison with long $f$-CNTs (L-MW 6a/b and $\mathbf{L}-\mathbf{M W} \mathbf{8 a} / \mathbf{b}$ ), can facilitate the interaction between the tubes and the enzyme in solution. Moreover, as confirmed by TGA (Fig. 3) and Kaiser test (Table 2), f-CNTs obtained by amidation reaction (L-MW 8a/b and SMW 9a/b) display a higher degree of functionalization compared with those functionalized by cycloaddition reaction (L-MW 6a/b 
and S-MW 7a/b). A higher amount of functional groups is also correlated to the presence of more defects on the graphitic surface. This was confirmed by Raman spectroscopy: L-MW 8a/b and S-MW $\mathbf{9 a} / \mathbf{b}$ display an $\mathrm{I}_{\mathrm{D}} / \mathrm{I}_{\mathrm{G}}$ value in the range of $0.38-0.39$ (Table 2 , entry 3 and 6 ), while the $I_{D} / I_{G}$ value for both $\mathbf{L}-\mathbf{M W ~} \mathbf{6 a} / \mathbf{b}$ and S-MW 7a/b corresponds to 0.23 (Table 2, entry 2 and 5 ). As a consequence, in the case of S-MW 9b, a good dispersibility together with a significant presence of functional and defect sites, probably offer the best conditions to induce a favorable interaction of the CNTs with the oxidative agents responsible for the tube degradation. The design of biodegradable nanotubes, through their length reduction and covalent organic derivatization, is of fundamental importance in view of the development of this type of materials for nanotechnology and biomedical applications.

In the case of functionalized DWCNTs, Raman analysis showed that this type of CNTs is more resistant to the degradation action of HRP (Table 2, entry 7-9). Indeed, in all cases, no significant increase in the D band intensity was observed after the treatment (see also Figures in Supporting Information). Since these tubes failed to degrade when incubated with HRP and $\mathrm{H}_{2} \mathrm{O}_{2}$, we conclude that defects and functionalized sites are not enough to promote any enzymatic action. Indeed, the Raman spectra of the $f$-DWCNTs already exhibit a really low intensity of the $\mathrm{D}$ band. Moreover, even after functionalization, the DWCNTs are prone to form strong aggregates that can hamper the accessibility of the enzyme active site to the defects of DWCNTs and slow down or prevent the degradation reaction. The presence of such aggregates made also difficult the analysis of the morphology of the nanotubes (i.e. possible shortening of the length), by means of TEM during the enzymatic treatment (see also Figures in Supporting Information). We expect that DWCNTs with a higher level of functionalization resulting in a higher dispersibility should be more degraded due to enhanced interactions with the enzyme. A similar behavior was recently evidenced on the degradation of graphene oxide [32]. Indeed, while the oxidative enzymes were able to completely degrade highly dispersed samples, it was not the case of a sample that was highly aggregated. Overall, these results provide further evidence that the presence of defects and/or functional groups, and the dispersibility of the material are key parameters that affect the biodegradability of CNTs.

\section{Conclusion}

The results reported in this work show the importance of the physico-chemical characteristics of the nanotubes, including the extent of existing structural defects on the carbon backbone, the dispersibility, and the role of chemical functionalization on the capacity of oxidative enzymes to degrade CNTs. We have demonstrated that the presence of functional groups on the CNTs can favor the biodegradation of MWCNTs, while DWCNTs are rather resistant to the enzymatic action, probably because of low dispersibility resulting in less interactions with the enzyme. The demonstration of biodegradability of $f$-CNTs has important implications in the biological impact of these materials, particularly related to any industrial and future biomedical applications. Further studies will be needed to address the possible risks associated with the degradation products of nanotubes rather than the intact nanomaterials.

\section{Acknowledgments}

This work was supported by the Centre National de la Recherche Scientifique (CNRS), by the Agence Nationale de la Recherche (ANR): DECANO project (ANR-2011-CESA-007-01) and LabEx project Chemistry of Complex Systems (ANR-10-LABX-0026_CSC), and by the International Center for Frontier Research in Chemistry
(icFRC). We would like to thank Petra Hellwig and Frédéric Melin for giving access to Raman instrument, and Dris Ihiawakrim for fruitful discussion. TEM was performed at the RIO Microscopy Facility Platform of Esplanade Campus, at the "Plateforme Imagerie in Vitro" at the Center of Neurochemistry (Strasbourg, France), and at the microcharacterisation Platform R. Castaing, UMS 3623 (Toulouse, France). We also would like to thank Frédéric Miserque (CEA-DEN Saclay, France) for XPS measurements and for fruitful discussions regarding the analysis of the spectra.

\section{Appendix A. Supplementary data}

Supplementary data related to this article can be found at http:// dx.doi.org/10.1016/j.carbon.2016.01.023.

\section{References}

[1] M.F.L. De Volder, S.H. Tawfick, R.H. Baughman, A.J. Hart, Carbon Nanotubes present and future commercial Applications, Science 339 (6119) (2013) 535-539.

[2] R.G. Mendes, A. Bachmatiuk, B. Büchner, G. Cuniberti, M.H. Rümmeli, Carbon nanostructures as multi-functional drug delivery platforms, J. Mater Chem. B 1 (4) (2013) 401-428.

[3] K. Kostarelos, A. Bianco, M. Prato, Promises, facts and challenges for carbon nanotubes in imaging and therapeutics, Nat. Nanotechnol. 4 (2009) 627-633.

[4] G. Hong, S. Diao, A.L. Antaris, H. Dai, Carbon nanomaterials for biological imaging and nanomedicinal therapy, Chem. Rev. 115 (19) (2015) 10816-10906.

[5] A. Battigelli, C. Ménard-Moyon, T. Da Ros, M. Prato, A. Bianco, Endowing carbon nanotubes with biological and biomedical properties by chemical modifications, Adv. Drug Deliv. Rev. 65 (2013) 1899-1920.

[6] Y. Liu, Y. Zhao, B. Sun, C. Chen, Understanding the toxicity of carbon nanotubes, Acc. Chem. Res. 46 (2013) 702-713.

[7] E.J. Petersen, L. Zhang, N.T. Mattison, D.M. O'Carroll, A.J. Whelton, N. Uddin, et al., Potential release pathways, environmental fate, and ecological risks of carbon nanotubes, Environ. Sci. Technol. 45 (2011) 9837-9856.

[8] M.J. Eckelman, M.S. Mauter, J.A. Isaacs, M. Elimelech, New perspectives on nanomaterial aquatic ecotoxicity: production impacts exceed direct exposure impacts for carbon nanotubes, Environ. Sci. Technol. 46 (2012) 2902-2910.

[9] A. Helland, P. Wick, A. Koehler, K. Schmid, C. Som, Reviewing the environmental and human health knowledge base of carbon nanotubes, Environ. Health Perspect. 115 (2007) 1125-1131.

[10] D.X. Flores-Cervantes, H.M. Maes, A. Scha, J. Hollender, Slow biotransformation of carbon nanotubes by horseradish peroxidase, Environ. Sci. Technol. 48 (9) (2014) 4826-4834.

[11] G.P. Kotchey, Y. Zhao, V.E. Kagan, A. Star, Peroxidase-mediated biodegradation of carbon nanotubes in vitro and in vivo, Adv. Drug Deliv. Rev. 65 (2013) 1921-1932.

[12] K. Bhattacharya, C. Sacchetti, R. El-Sayed, A. Fornara, G.P. Kotchey, J.A. Gaugler, et al., Enzymatic 'stripping' and degradation of PEGylated carbon nanotubes, Nanoscale 6 (24) (2014) 14686-14690.

[13] Y. Zhao, B.L. Allen, A. Star, Enzymatic degradation of multiwalled carbon nanotubes, J. Phys. Chem. A 115 (2011) 9536-9544.

[14] J. Russier, C. Ménard-Moyon, E. Venturelli, E. Gravel, G. Marcolongo, M. Meneghetti, et al., Oxidative biodegradation of single- and multi-walled carbon nanotubes, Nanoscale 3 (3) (2011) 893-896.

[15] X. Liu, R.H. Hurt, A.B. Kane, Biodurability of single-walled carbon nanotubes depends on surface functionalization, Carbon 48 (2010) 1961-1969.

[16] V.E. Kagan, N.V. Konduru, W. Feng, B.L. Allen, J. Conroy, Y. Volkov, et al., Carbon nanotubes degraded by neutrophil myeloperoxidase induce less pulmonary inflammation, Nat. Nanotechnol. 5 (2010) 354-359.

[17] B.L. Allen, P.D. Kichambare, P. Gou, Vlasova II, A.A. Kapralov, N. Konduru, et al., Biodegradation of single-walled carbon nanotubes through enzymatic catalysis, Nano Lett. 8 (11) (2008) 3899-3903.

[18] L. Zhang, E.J. Petersen, M.Y. Habteselassie, L. Mao, Q. Huang, Degradation of multiwall carbon nanotubes by bacteria, Environ. Pollut. 181 (2013) 335-339.

[19] D. Elgrabli, W. Dachraoui, C. Ménard-Moyon, X.J. Liu, D. Bégin, S. Bégin, et al., Carbon nanotube degradation in macrophages: live nanoscale monitoring and understanding of biological pathway, ACS Nano 9 (10) (2015) 10113-10124.

[20] B.L. Allen, G.P. Kotchey, Y. Chen, N.V.K. Yanamala, J. Klein-seetharaman, V.E. Kagan, Mechanistic investigations of horseradish peroxidase-catalyzed degradation of single-walled carbon nanotubes, J. Am. Chem. Soc. 131 (47) (2009) 17194-17205.

[21] C. Zhang, W. Chen, P.J.J. Alvarez, Manganese peroxidase degrades pristine but not surface-oxidized (carboxylated) single-walled carbon nanotubes, Environ. Sci. Technol. 48 (14) (2014) 7918-7923.

[22] K. Bhattacharya, R. El-Sayed, F.T. Andón, S.P. Mukherjee, J. Gregory, H. Li, et al., Lactoperoxidase-mediated degradation of singlewalled carbon nanotubes in the presence of pulmonary surfactant, Carbon 91 (2015) 506-517.

[23] V. Neves, E. Heister, S. Costa, C. Tîlmaciu, E. Borowiak-Palen, C.E. Giusca, et al., 
Uptake and release of double-walled carbon nanotubes by mammalian cells Adv. Funct. Mater 20 (19) (2010) 3272-3279.

[24] A.R. Sureshbabu, R. Kurapati, J. Russier, C. Ménard-Moyon, I. Bartolini, M. Meneghetti, et al., Degradation-by-design: surface modification with functional substrates that enhance the enzymatic degradation of carbon nanotubes, Biomaterials 72 (2015) 20-28.

[25] Y. Sato, A. Yokoyama, Y. Nodasaka, T. Kohgo, K. Motomiya, H. Matsumoto, et al., Long-term biopersistence of tangled oxidized carbon nanotubes inside and outside macrophages in rat subcutaneous tissue, Sci. Rep. 3 (2516) (2013) 10

[26] D. Mata, M. Amaral, A.J. Fernandes, B. Colaço, A. Gama, M.C. Paiva, et al., DielsAlder functionalized carbon nanotubes for bone tissue engineering: in vitro in vivo biocompatibility and biodegradability, Nanoscale 7 (2015) 9238-9251.

[27] A.E. Goode, D.A. Gonzalez Carter, M. Motskin, I.S. Pienaar, S. Chen, S. Hu, et al, High resolution and dynamic imaging of biopersistence and bioreactivity of extra and intracellular MWNTs exposed to microglial cells, Biomaterials 70 (2015) 57-70
[28] A. Bianco, K. Kostarelos, M. Prato, Making carbon nanotubes biocompatible and biodegradable, Chem. Commun. (Camb) 47 (37) (2011) 10182-10188.

[29] H. Ali-Boucetta, A. Nunes, R. Sainz, M.A. Herrero, B. Tian, M. Prato, et al, Asbestos-like pathogenicity of long carbon nanotubes alleviated by chemical functionalization, Angew. Chem. Int. Ed. Engl. 52 (8) (2013) 2274-2278.

[30] C. Castro, M. Pinault, D. Porterat, C. Reynaud, M. Mayne-L'Hermite, The role of hydrogen in the aerosol-assisted chemical vapor deposition process in producing thin and densely packed vertically aligned carbon nanotubes, Carbon 61 (2013) 585-594.

[31] M. Mouchet, P. Landois, P. Puech, E. Pinelli, E. Flahaut, L. Gauthier, CNT ecotoxicity in amphibians: assessment of multi-walled carbon nanotubes and comparison with double-walled carbon nanotubes, Nanomedicine 5 (6) (2010) 963-974.

[32] R. Kurapati, J. Russier, M.A. Squillaci, E. Treossi, C. Ménard-Moyon, A.E. Del Rio-Castillo, et al., Dispersibility-dependent biodegradation of graphene oxide by myeloperoxidase, Small 11 (32) (2015) 3985-3994. 